\title{
Prevalência de hematúria enzoótica bovina em rebanhos leiteiros na microrregião do Caparaó, Sul do Espírito Santo, entre 2007 e 2008
}

\author{
Prevalence of bovine enzootic haematuria in dairy cattle in the Caparaó microregion, southern \\ Espirito Santo, between 2007 and 2008
}

\author{
Maria Aparecida da Silva ${ }^{I}$ Camila Mognato ScárduaII Marcus Dantas DóreaIII \\ Louisiane de Carvalho Nunes ${ }^{\mathrm{IV}}$ Isabella Vilhena Freire Martins $^{\mathrm{IV}}$ Dirlei Molinari Donatele ${ }^{\mathrm{IV}}$
}

RESUMO

A hematúria enzoótica bovina (HEB) é uma doença crônica que tem causado grandes perdas econômicas aos proprietários da microrregião do Caparaó, na região Sul do Estado do Espírito Santo (ES). O objetivo deste trabalho foi obter a prevalência e os achados hematológicos de bovinos com hematúria enzoótica decorrente de intoxicação natural por Pteridium aquilinum (samambaia) no período de março de 2007 a abril de 2008, na microrregião do Caparaó, ES. Foram visitadas 50 propriedades onde foi constatada a presença da planta em todos os 10 municípios avaliados. Cento e oitenta e um bovinos foram examinados e 39 estavam doentes. Dentre os afetados, 22 (56,4\%) apresentavam HEB, todos provenientes dos Municípios de Guaçuí, Divino de São Lourenço, Iúna, Ibatiba e Ibitirama. Os bovinos tinham macrohematúria, e os valores do hematócrito mostraram-se baixos, variando de $8 \%$ a $31 \%$. A leucometria total teve valor médio de $132 \times 10^{3} \mathrm{~mm}^{-3}$, revelando leucocitose. A temperatura e o tempo de preenchimento capilar (TPC) estavam dentro da normalidade. Quatro bovinos (18,2\%) tinham mucosas anêmicas. Nota-se que a prevalência de $\mathrm{HEB}$, na microrregião do Caparaó, ES, é alta e que há a necessidade de novos estudos para diminuir as perdas econômicas causadas por essa doença.

Palavras-chave: doenças de bovinos, hematúria enzoótica bovina, Pteridium aquilinum, samambaia, epidemiologia.

\section{ABSTRACT}

Bovine enzootic hematuria (BEH) is a chronic disease that has been causing great economic losses to farmers of the Caparaó microregion, southern Espírito Santo State.
The objective of this study was to evaluate the prevalence of cattle naturally affected by poisoning by Pteridium aquilinum (bracken fern) with clinical hematuria between 2007 and 2008 and establish the hematologic findings of these animals. Fifty facilities were visited and the plant was observed in all of the ten evaluated municipal districts. One hundred and eighty one bovines were examined and 39 animals were sick. Among the affected cattle, 22 (56.4\%) presented BEH. Affected animals were from Guaçuí, Divino de São Lourenço, Iúna, Ibatiba and Ibitirama districts. The animals had macrohematuria and the values of the hematocrit were low, ranging between 8 and $31 \%$. The total leukometry had the mean value of $132 \times 10^{3} \mathrm{~mm}^{-3}$, showing leukocytosis. The temperature and capillary refill time were normal. Four animals $(18.2 \%)$ had pale mucosal surfaces. It was noted that the $\mathrm{BEH}$ prevalence in the Caparao microregion, ES, is high and there is a great necessity of new studies to reduce the economic losses caused by this disease.

Key words: diseases of cattle, bovine enzootic hematuria, Pteridium aquilinum, bracken fern, epidemiology.

\section{INTRODUÇÃO}

A hematúria enzoótica bovina (HEB) é uma doença não infecciosa e crônica, causada pela intoxicação por Pteridium aquilinum (L.) Kühn, que se caracteriza pelo desenvolvimento de neoplasmas na mucosa da bexiga, os quais cursam clinicamente com hematúria intermitente e morte por anemia (RADOSTITIS et al., 2007), já que ocorre perda de

IPrograma de Residência em Medicina Veterinária em Patologia Animal, Centro Universitário de Vila Velha (UVV), Vila Velha, ES, Brasil.

IIMédica Veterinária Autônoma, João Neiva, ES, Brasil.

IIIPrograma de Pós-graduação em Ciências Veterinárias, Universidade Federal do Espírito Santo (UFES), Alegre, ES, Brasil.

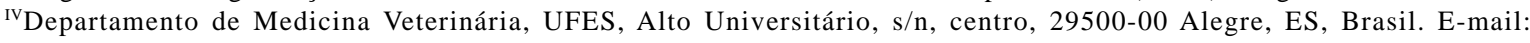
louisiane@cca.ufes.br.*Autor para correspondência. 
sangue sem reposição pela medula (anemia aplástica). Vacas prenhes podem abortar (MARÇAL et al., 2001). O diagnóstico de HEB é estabelecido com base na epidemiologia, em sinais clínicos e nas lesões macroscópicas e microscópicas da bexiga (SOUTO et al., 2006).

A HEB ocorre quando há a ingestão de $\boldsymbol{P}$. aquilinum por bovinos em uma quantidade inferior a $10 \mathrm{~g} \mathrm{~kg}^{-1} \mathrm{dia}^{-1}$, durante um ou mais anos (TOKARNIA et al., 2000). A fome é o principal fator que leva os bovinos a ingerirem a planta, devido à superlotação do pasto, à falta de material fibroso na alimentação ou a períodos de seca (pós-inverno). Os bovinos que são colocados no pasto infestado após transportes prolongados, o hábito de ingerir a planta e o uso de feno contaminado são outras causas que podem levar a um quadro de intoxicação por $\boldsymbol{P}$ a aquilinum (GAVA, 1994). A planta ocorre principalmente em regiões frias e de boa pluviosidade, com solos ácidos e bem drenados (encostas de morro) (TOKARNIA et al., 2000).

No Brasil, em locais onde $\boldsymbol{P}$. aquilinum é abundante (SOUTO et al., 2006), a HEB tem sido responsável por perdas econômicas significativas (TOKARNIA et al., 2000). Na microrregião do Caparaó, Espírito Santo (ES), a HEB é uma das principais doenças que afetam o gado leiteiro. Segundo os proprietários da região, o quadro clínico de hematúria com anemia e caquexia tem sido frequente e gera perdas econômicas de cerca de $\mathrm{R} \$ 30.000,00$ por proprietário/ano (comunicação informal obtida do produtor Gilson Vimercatti, município de Ibitirama-ES).

A estrutura social da região se caracteriza por municípios pequenos, com grande população rural, sendo o contexto agropecuário representado por um modelo de agricultura familiar. A atividade agropecuária da região é caracterizada por baixo nível tecnológico, mão-de-obra pouco qualificada, deficiência na assistência médico-veterinária e gestão não empreendedora, verificando-se, em muitos casos, como atividade de subsistência (SCARDUA, dados não publicados).

A microrregião do Caparaó apresenta diferenças topográficas e climáticas, composição do solo, bacias hidrográficas, dentre outras características, como o manejo do rebanho, que, sozinhas ou em conjunto, podem influenciar condições epidemiológicas para a ocorrência de $\boldsymbol{P}$. aquilinum e HEB.

Diante do que foi exposto, nota-se que ainda não existem informações elucidativas relacionadas à HEB na região, onde $\boldsymbol{P}$. aquilinum existe em vasta escala. Portanto, o objetivo deste trabalho foi obter dados sobre a prevalência e os achados hematológicos de bovinos afetados pela HEB microrregião do Caparaó, na região Sul do Estado do ES, no período de março de 2007 a abril de 2008.

\section{MATERIAL E MÉTODOS}

Foram visitadas 50 propriedades de bovinos leiteiros da microrregião do Caparaó, região Sul do Estado do ES, no período de março de 2007 a abril de 2008. Foram selecionadas cinco propriedades por município, utilizando-se a técnica de amostragem aleatória simples. Essa microrregião é formada por 10 municípios: Iúna, Ibatiba, Ibitirama, Irupi, Dores do Rio Preto, Divino São Lourenço, Guaçuí, Muniz Freire, Alegre e São José do Calçado.

Para o agendamento das visitas, utilizou-se listagem obtida por meio do cadastro do Instituto de Defesa Agropecuária e Florestal do Espírito Santo (IDAF-ES) e das Secretarias Municipais de Agricultura. Os produtores foram contatados por telefone para confirmação de sua atividade na produção de leite. Do total de bovinos destinados à produção leiteira, 10\% foram selecionados para realização de exame clínico e avaliação da existência de hematúria. A escolha dos bovinos era feita pelo produtor, por conveniência.

Todos os bovinos selecionados foram examinados. Foram verificados o tempo de perfusão capilar (TPC), a coloração das mucosas, a temperatura corporal e a inspeção geral (avaliando o estado nutricional e a presença de lesões cutâneas, neoplasmas, linfadenopatia, diarréia e hematúria).

De cada bovino foram coletados $10 \mathrm{~mL}$ de sangue total por meio de punção da veia caudal, em tubos a vácuo, estéreis com anticoagulante sal disódico do ácido diaminotetracético (EDTA), para a realização de hematócrito e leucometria universal. A coleta de urina foi realizada por micção espontânea em todos os bovinos que apresentavam urina escura verificada pelo proprietário. Nessa avaliação era confirmada ou não a existência de hematúria, de acordo com os critérios descritos por FALBO et al. (2005).

Todas as amostras coletadas foram acondicionadas em isopor contendo gelo e enviadas ao Laboratório Clínico do Hospital Veterinário da Universidade Federal do Espírito Santo.

\section{RESULTADOS E DISCUSSÃO}

Das 50 propriedades visitadas, foram examinados 181 bovinos, representando a amostragem de $10 \%$ do total de bovinos em lactação, escolhidos por conveniência pelo proprietário. Os animais eram predominantemente da raça Girolando, sendo 180 fêmeas em lactação e um macho, de idades variadas.

Do total de bovinos examinados, 39 apresentaram alguma enfermidade. Destes, 22 (56,4\%) apresentaram hematúria, seis $(15,4 \%)$ afecções podais, 
quatro $(10,2 \%)$ afecções oculares, quatro $(10,2 \%)$ apresentaram mastite e três $(7,8 \%)$ apresentaram problemas digestivos. Serão descritos neste trabalho apenas os resultados dos exames clínicos e hematológicos encontrados nos bovinos com hematúria.

Os 22 (56,4\%) bovinos que apresentaram quadro de hematúria eram fêmeas, com idade variando entre quatro e 14 anos. O diagnóstico foi estabelecido pela existência de macrohematúria e pela presença de $\boldsymbol{P}$. aquilinum na propriedade. Ao ocorrerem as manifestações clínicas da intoxicação por $\boldsymbol{P}$ aquilinum em bovinos, a primeira conduta diagnóstica deve ser a constatação da planta na propriedade (MARÇAL, 2003).

O número de casos de HEB encontrados por municípios foi variável. Foram observados 12 casos (54,6\%) em Ibitirama, sete casos (31,9\%) em Ibatiba, um caso (4,5\%) em Iúna, um caso (4,5\%) em Guaçuí e um caso (4,5\%) em Divino de São Lourenço. Nos demais municípios que compõem a microrregião do Caparaó, nenhum caso foi encontrado.

P. aquilinum foi encontrada em todos os municípios visitados. As zonas geográficas onde essa planta geralmente ocorre têm solos ácidos, pobres e com baixos níveis de cálcio e fósforo (DURÃO et al., 1995). Isso também ocorre nos municípios da microrregião do Caparaó (INSTITUTO JONES DOS SANTOS NEVES, 2008). No entanto, foram diagnosticados bovinos com quadro clínico de HEB em apenas cinco (50\%) municípios. Isso pode ser explicado devido ao fato de que as cidades de Ibitirama, Ibatiba, Iúna, Guaçuí e Divino de São Lourenço estão localizadas em altas altitudes, e os aspectos geográficos da região também podem interferir na toxicidade da $\boldsymbol{P}$. aquilinum (ALONSO-AMELOT, 1999).

Em um estudo de casos de HEB no Paraná, foi observado que, de um total de 237 bovinos examinados, nove $(3,8 \%)$ apresentaram quadro de hematúria (FALBO et al., 2005). Dados semelhantes foram descritos na região Sul, onde se observou que, do total de 2.912 laudos de necropsia de bovinos avaliados no período de 1990 a 2005, 461 (15,8\%) tinham diagnóstico de intoxicação por plantas. Destes, 55 $(12,1 \%)$ tinham diagnóstico de intoxicação por $\boldsymbol{P}$. aquilinum. Desses bovinos, apenas quatro $(7,3 \%)$ apresentaram HEB (RISSI et al., 2007). Em outro estudo, conduzido em Santa Catarina (GAVA et al., 2002), foi observado que, de um total de 3.407 bovinos necropsiados, 7,2\% apresentaram intoxicação por $\boldsymbol{P}$. aquilinum. Destes, apenas 19 (0,6\%) desenvolveram quadro de HEB. Um estudo recente (SOUTO et al., 2006) demonstrou que, em 33 casos de intoxicação por $\boldsymbol{P}$. aquilinum na região de Jaguari, Rio Grande do Sul (RS), no período de setembro de 2003 a agosto de 2005, apenas três casos de HEB foram diagnosticados. Esses dados indicam que a prevalência de HEB na região Sul é mais baixa do que na microrregião do Caparaó, ES.

Dos bovinos com hematúria avaliados neste estudo, todos apresentaram temperatura dentro da normalidade, variando de $38,1^{\circ} \mathrm{C}$ a $39,5^{\circ} \mathrm{C}$, com média de $38,8^{\circ} \mathrm{C}$. O TPC variou de um a três segundos (média de dois segundos). A avaliação das mucosas não constatou anormalidades em $18(81,8 \%)$ casos e revelou anemia em quatro $(18,2 \%)$. Os valores do hematócrito variaram de $8 \%$ a $31 \%$, sendo a média de $20 \%$. A leucometria total variou de 60 a $215 \times 10^{3} \mathrm{~mm}^{-3}$, sendo o valor médio encontrado $132 \times 10^{3} \mathrm{~mm}^{-3}$. Os valores de hematócrito observados neste estudo estão baixos se comparados aos citados na literatura (FELDMAN et al., 2000).

SINGH et al. (1972) verificaram redução considerável do hematócrito e da hemoglobina com anemia progressiva devido à perda de sangue pela urina em bovinos com HEB. SÁNCHEZ-VILLALOBOS et al. (2006) também encontraram redução nos valores do hematócrito de bovinos intoxicados que apresentavam HEB.

Os valores encontrados para contagem de leucócitos totais estão aumentados (RADOSTITIS et al., 2007). Esses dados são sustentados pelo fato de que bovinos com quadro clínico de HEB podem desenvolver uma condição inflamatória crônica (SINGH et al., 1972).

O alto índice de anemia observado nos bovinos deste estudo está diretamente relacionado à macrohematúria. Em um estudo, bovinos com HEB e macrohematúria tiveram o hematócrito variando entre $15 \%-45 \%$, com média de $31 \%$, enquanto que bovinos com microhematúria tiveram hematócrito variando de 21\%-48\%, com média de 36\% (FALBO et al., 2005) Segundo esses mesmos autores, bovinos que apresentam microhematúria, ou seja, que apresentam mais de 5.000 hemácias $\mathrm{mL}^{-1}$ de urina, podem não apresentar sinais de anemia e dificultar o diagnóstico clínico de HEB. As alterações hematológicas geralmente tornam-se evidentes com o início da macrohematúria (RAJENDRAN et al., 1983), semelhante ao que foi observado neste estudo.

É importante estabelecer o diagnóstico diferencial entre hematúria, em que se observa formação de sedimento urinário, e hemoglobinúria, em que esse sedimento não se forma (MARÇAL, 2000).

O valor médio observado para o TPC foi de dois segundos, o que é considerado normal (RADOSTITIS et al., 2007). Esses mesmos autores 
descrevem que um TPC de três segundos ou mais, acompanhado por mucosas orais cianóticas, indica um prognóstico desfavorável.

Durante o desenvolvimento do trabalho, foi solicitada a realização de eutanásia e necropsia em um bovino. O animal apresentava hematócrito de $9 \%$ e estava caquético. Ao exame macroscópico, observaramse hidronefrose bilateral, trombose da artéria renal direita e consequente infarto renal. Na bexiga, foram encontradas massas irregulares de coloração amarelada. Histologicamente essas massas consistiam de adenocarcinoma e carcinoma de células de transição (NUNES et al., dados não publicados).

Segundo TOKARNIA et al. (2000), o exame histopatológico das lesões observadas na bexiga de bovinos com HEB revela diversos tipos de processos neoplásicos de origem epitelial e mesenquimal, e o mesmo animal pode apresentar diversos tipos de tumores. Isso também foi observado por PEIXOTO et al. (2003), os quais encontraram histogênese variada nos tumores de bovinos com HEB.

\section{CONCLUSÕES}

Com base nos dados obtidos neste estudo, verificou-se que a prevalência de HEB em bovinos leiteiros, na microrregião do Caparaó, Sul do Estado do Espírito Santo, é alta. A doença foi mais comum nos municípios que apresentam as maiores altitudes e as temperaturas baixas.

\section{REFERÊNCIAS}

ALONSO-AMELOT, M.E. Helecho macho, salud animal y salud humana. Revista de la Facultad de Agronomía, v.16, p.528-541, 1999.

DURÃO, C.J.F. et al. Pathological and clinical aspects of bovine enzootic hematuria. Revista Portuguesa de Ciências Veterinárias, v.90, n.515, p.132-137, 1995.

FALBO, M.K. et al. Alterações hematológicas, bioquímicas, urinárias e histopatológicas na intoxicação natural pela samambaia Pteridium aquilinum (L.) Kühn. Semina: Ciências Agrárias, v.16, n.4, p.547-558, 2005.

FELDMAN, B.F. et al. Schalm's veterinary hematology. 5.ed. Philadelphia: Lippincott Williams e Wilkins, 2000. 1344p.

GAVA, A. Intoxicações por plantas de ação antihematopoiética e mutagênica. In: RIET-CORREA, F. et al. Doenças de ruminantes e equinos. 2.ed. Pelotas: UFPel, 1994. p.247258.
GAVA, A. et al. Bracken fern (Pteridium aquilinum) poisoning cattle in southern Brazil. Veterinary and Human Toxicology, v.44, n.6, p.362-365, 2002.

INSTITUTO JONES DOS SANTOS NEVES, INDDES. Regiões. Disponível em: http://www.ijsn.es.gov.br. On line. Acesso em 04 de setembro de 2008.

MARÇAL, W.S. A toxidez da samambaia nos bovinos. 2000. Disponível em: http://www.saudeanimal.com.br/bovinosamambaia.htm. On line. Acesso em: 30 jun. 2008.

MARÇAL, W.S. et al. Ocorrência de intoxicação aguda em bovinos pela samambaia (Pteridium aquilinum L. Kuhn) no norte do Paraná-Brasil. Semina: Ciências Agrárias, v.22, n.2, p. 139-144, 2001.

MARÇAL, W.S. A intoxicação por samambaia em bovinos criados no Estado do Paraná. Semina: Ciências Agrárias, v.24, n.1, p.197-208, 2003.

PEIXOTO, P.V. et al. Histopathological aspects of bovine enzootic hematuria in Brazil. Pesquisa Veterinária Brasileira, v.23, n.2, p. 65-81, 2003. Disponível em: <http:/ /www.scielo.br/scielo.php?pid=S0100736X200300 $0200004 \&$ script $=$ sci_arttext\&tlng $=$ en $>$. Acesso em 15 abr. 2009. doi: 10.1590/S0100-736X2003000200004.

RADOSTITIS, O.M. et al. Veterinary medicine. A textbook of the diseases of cattle, horses, sheep, pigs and goats. 10.ed. London: Saunders, 2007. 2065p.

RAJENDRAN, M.P. et al. Experimental production of enzootic bovine haematuria with bracken fern. Indian Journal of Veterinary Science, v.60, n.3, p.173-178, 1983.

RISSI, D.R. et al. Intoxicações por plantas e micotoxinas associadas a plantas em bovinos no Rio Grande do Sul: 461 casos. Pesquisa Veterinária Brasileira, v.27, n.7, p.261268, 2007. Disponível em: <http://www.scielo.br/ scielo.php ? script =sci_arttext\&pid=S 0100 $736 \times 2007000700002 \& \operatorname{lng}=p t \& n r m=i s o>$. Acesso em 15 abr.2009. doi: 10.1590/S0100-736X2007000700002.

SÁNCHEZ-VILLALOBOS, A. et al. Validez, seguridad y cociente de verosimilitud de los métodos tiras reactivas para orina y examen microscópico del sedimento urinario en el diagnóstico de hematuria enzoótica bovina. Revista Científica, FCV-LUZ, v.16, n.6, p.604-612, 2006.

SINGH, A.K. et al. Studies on bovine haematuria. I. Haematological and biochemical observations on the blood of cattle suffering from haematuria. Indian Journal of Animal Science, v.43, n.4, p.296-299, 1972.

SOUTO, M.A.M. et al. Neoplasmas da bexiga associados à hematúria enzoótica. Ciência Rural, v.36, n.5, p.16471650, 2006. Disponível em: <http://www.scielo.br/ s c i e l o.p h p ? p i d = S 010038477820006 $000500050 \&$ script $=$ sci_arttext $\&$ tlng $=p t>$. Acesso em 15 abr. 2009. doi: 10.1590/S0103-84782006000500050.

TOKARNiA, C.H. et al. Plantas tóxicas do Brasil. Rio de Janeiro: Helianthus, 2000. 310p. 